\title{
Gobierno corporativo y grupos económicos en México: especial referencia a los deberes de lealtad y diligencia
}

\author{
Carlos Ernesto Arcudia Hernández \\ carlosarcudia@gmail.com \\ Profesor Investigador de la Universidad Autónoma de San Luis Potosí \\ México
}

\section{Resumen}

El gobierno corporativo procura resolver los problemas de agencia que se presentan entre los accionistas entre sí y los accionistas y los administradores de las sociedades. Estos problemas se presentan de forma diferenciada según el modelo de arquitectura organizacional. En México la arquitectura predominante es la de los grupos económicos. Estas redes de empresas presentan una fuerte centralización de la propiedad y del control. Característica que se ha ido incrementando desde 1982. Pues bien, dada la estructura de propiedad y control de los grupos económicos mexicanos se analizarán dos deberes que les impone la Ley del Mercado de Valores a los administradores de las Sociedades Anónimas Bursátiles mexicanas: el deber de lealtad y el deber de diligencia.

Palabras clave: Gobierno Corporativo, Grupos Económicos, Deber de lealtad, deber de diligencia, arquitectura organizacional

\begin{abstract}
Corporate governance intends to solve agency problems among shareholders themselves and the managers of the companies. These problems appear in a differentiated way according to the model of organizational structure. The prevailing structure in Mexico is that of the conglomerates. These companies' networks have a strong centralization of property and control. This has been increasing since 1982. Then, according to the structure of property and control
\end{abstract}

Recibido: 20-10-2013 - Versión final aceptada: 15-11-2013 
of the Mexican conglomerates, the duties of loyalty and diligence imposed to managers of the Mexican Stock limited companies by the Law of the Stock Market will be analyzed.

Key words: Corporate governance, conglomerate, duty of loyalty, duty of diligence, organizational structure.

\section{Introducción}

Durante mucho tiempo, la gran compañía mercantil se ha reconducido a un modelo caracterizado por la separación entre los titulares de los recursos necesarios para llevar a cabo el proyecto empresarial y los gestores de ese proyecto, y por consiguiente, también de esos recursos. Aunque la ficción legal de la personalidad jurídica proporcione una imagen distorsionada de ese modelo, esa descripción es perfectamente admisible. Esta separación entre propiedad y control de la empresa da lugar a lo que se conoce como "problemas de agencia". Desde el movimiento del Gobierno Corporativo se han ideado algunas soluciones para superar los problemas de agencia que enfrentan a los accionistas con los administradores.

En el presente trabajo, se pretende realizar un análisis legal de las soluciones que desde los diferentes órdenes normativos mercantiles y bursátiles han agravado los deberes de lealtad y de diligencia de los administradores se las sociedades y en correlativo las acciones de responsabilidad. Para ello se hará la conceptualización del gobierno corporativo; así como un breve repaso de los principales problemas de agencia a los que intenta dar solución.

Para poder comprender mejor el impacto de las medidas del Gobierno Corporativo es necesario caracterizar los modelos de arquitectura organizacional de las grandes corporaciones en el mundo, a saber: el modelo alemán, el modelo anglosajón, el modelo japonés y el de grupos económicos. Se hará hincapié en este último ya que es el modo de regulación dominante en la economía mexicana. Se tratarán sus características generales y se profundizará sobre su evolución. Esta última se ha caracterizado por un fuerte proceso de concentración y centralización del dinero y del poder que tiene una red de administradores también centralizada. 
Una vez descrito el modelo de los grupos económicos se hará un repaso breve de las medidas propuestas por el movimiento del Gobierno Corporativo para solucionar los problemas de agencia. Ante la imposibilidad, por razones de extensión, de abarcar el análisis puntual de cada una de las medidas, únicamente se estudiará la regulación de los deberes de lealtad y de diligencia de los administradores. Por último, se analizará la acción de responsabilidad por medio de la cual se puede exigir el cumplimiento judicial de tales deberes.

\section{El gobierno corporativo y los problemas de agencia}

Cualquier sistema de gobierno corporativo está compuesto por un conjunto heterogéneo de instrumentos de salvaguardia y supervisión cuya finalidad es alinear los incentivos de los insiders [el equipo directivo y, en su caso, el grupo de control] y los intereses de los outsiders [los accionistas minoritarios]. Los que a renglón seguido se enumeran son seguramente los más importantes, aunque su eficacia relativa depende del contexto institucional de cada mercado: (i) la constitución de un consejo de administración con alta capacidad de supervisión de la instancia ejecutiva de la compañía; (ii) el establecimiento de un sistema de opas y de mecanismos de lucha para la obtención de delegaciones de votos, que faciliten la competencia por el control; (iii) el diseño de sistemas de remuneración y contratos de incentivos capaces de reconciliar los intereses de los managers y los intereses de los inversores; (iv) la concentración parcial de la propiedad y la centralización del control en manos de uno o varios accionistas de referencia con incentivos suficientes para vigilar al management; (v) el reposicionamiento de los inversores institucionales como fuerzas proactivas en los foros de accionistas; y (vi) la implantación de un sistema efectivo de responsabilidad de los administradores con una adecuada definición de sus deberes fiduciarios [Paz Ares. 2003: 3].

Existe consciencia generalizada, incluso entre los juristas, de que el gobierno de las compañías es un factor esencial de la competitividad. Las diferentes formas organizativas que pueden adoptar la empresa no poseen el mismo grado de eficiencia frente al mercado ${ }^{1}$. Aunque mercado

1 Empresa y mercado son dos instituciones que cumplen objetivos análogos: promover que los recursos se apliquen en empleos más útiles (Bisbal I Mendez, 1997: 1675). 
y empresa compiten como mecanismos de coordinación de conductas y asignación de recursos lo hacen de forma diferente. Decían los economistas que en el mercado el mecanismo es el de los precios, mientras que en la empresa es el de la explícita dirección de las actividades, realizada por la propia organización empresarial; más adelante, los economistas advirtieron que en ambos casos, en el mercado y en la empresa, el mecanismo de coordinación de conductas y de asignación de recursos tenía la misma base contractual. Con todo y teniendo en cuenta el fundamento contractual de ambos mecanismos, la administración de cada tipo de contrato, y el género de costes en que hay que incurrir para llevarlo a cabo, son distintos. Los costes de administrar los contratos en el mercado se denominan "costes de transacción", mientras que los constes de administrar el complejo conjunto de contratos que se entrelazan en la empresa, se denominan "costes de agencia" [Bisbal I Méndez, 1997: 1676-1977].

Con el fin de limitar los conflictos de intereses y controlar la gestión de los administradores, los accionistas [principales] tendrán que adoptar una serie de medidas e incentivar a los administradores [agentes] con el fin de asegurarse que su comportamiento no les ocasione perjuicio en su patrimonio. Ahora bien, siempre existirá un cierto margen de diferencia entre los intereses de ambas partes: los costes de agencia. Los costes de agencia se integran por la suma de: "los gastos de vigilancia realizados por el principal para evitar conductas no deseadas en el agente [monitoring expenditures], los gastos de garantía [bonding costs] con los cuales el principal pretende asegurarse de que el agente no realizará determinadas acciones que irían en contra de sus intereses o de que será compensado en caso de que las realice; y aquella pérdida residual [residual loss] que, a pesar de los dos gastos anteriores sufrirá el principal por la diferencia aun pequeña, que siempre habrá entre la actuación del agente y la actuación ideal que hubiese generado el máximo beneficio del principal" [Guerra Martín, 2003: 122].

Los problemas de agencia que se pueden presentar en una sociedad de gran tamaño son básicamente tres: (i) accionistas enfrentados con administradores y gestores; (ii) accionistas mayoritarios enfrentados a los minoritarios; y, (iii). accionistas contra acreedores. Estos problemas, se caracterizan en la tabla 1. 
Tabla 1.- Principales problemas de agencia

\begin{tabular}{|l|l|l|}
\hline Accionistas vs. gestores & $\begin{array}{c}\text { Accionistas mayoritarios } \\
\text { vs. accionistas } \\
\text { minoritarios }\end{array}$ & \multicolumn{1}{|c|}{$\begin{array}{c}\text { Accionistas vs. } \\
\text { acreedores }\end{array}$} \\
\hline $\begin{array}{l}\text { Los administradores de- } \\
\text { berán conducir la socie- } \\
\text { dad orientándose en el } \\
\text { interés social que coinci- } \\
\text { de con el de los accionis- } \\
\text { tas, pero esto no siempre } \\
\text { puede ser así. Estamos } \\
\text { ante los problemas gene- } \\
\text { rados por la administra- } \\
\text { ción heterónoma de la } \\
\text { sociedad. }\end{array}$ & $\begin{array}{l}\text { de en seno } \\
\text { toman las decisiones im- } \\
\text { portantes, una mayoría de } \\
\text { socios puede afectar los } \\
\text { derechos de la minoría. }\end{array}$ & $\begin{array}{l}\text { Una decisión adoptada } \\
\text { por los socios en be- } \\
\text { neficio propio podría } \\
\text { acarrear perjuicios a los } \\
\text { acreedores. }\end{array}$ \\
\hline
\end{tabular}

\section{Arquitectura organizacional en México: los grupos económicos}

Las formas que asumen la arquitectura y el gobierno corporativos en cada país son resultado de patrones socioculturales formados durante largos períodos ${ }^{2}$. Dadas las condiciones de cada nación, ciertas formas de arquitectura y gobierno pueden facilitar la inversión, la innovación y el desarrollo económico, mientras que en otros casos no es así. En particular, las combinaciones entre arquitectura y gobierno ayudan a definir los sistemas de negocios. Estos sistemas son diferentes entre países porque resultan de distintos patrones de propiedad, control y vínculos corporativos [Chavarín 2010: 14].

Así, los principales modelos de arquitectura organizacional se pueden clasificar en anglosajón, alemán, japonés y grupos económicos. En la tabla 2 se detallan las características de cada uno de los modos.

\footnotetext{
El concepto arquitectura empresarial se refiere a los tipos de acuerdos y relaciones que las unidades productivas establecen entre sí con el propósito de organizar sus transacciones. El gobierno corporativo involucra a los arreglos institucionales, formales e informales, con que las empresas y redes de negocios resuelven los conflictos surgidos de la interrelación de los actores participantes (Chavarin, 2006, p 194).
} 


\section{Tabla 2. Principales modelos de arquitectura organizacional}

\begin{tabular}{|c|c|}
\hline Anglosajón & $\begin{array}{l}\text { Los países más representativos de este modelo son Estados Unidos } \\
\text { y Gran Bretaña. En estas naciones la estructura de propiedad } \\
\text { empresarial se caracteriza por un accionariado disperso. En estos } \\
\text { mercados las empresas suelen ser más independientes, ya que } \\
\text { no están controladas por un grupo reducido de accionistas, que } \\
\text { normalmente se reduce a un grupo familiar, ni son habituales } \\
\text { las participaciones cruzadas entre empresas, siendo sin embargo } \\
\text { muy importante la presencia de inversores institucionales. En este } \\
\text { modelo, la transferencia de la propiedad y el control de las empresas } \\
\text { suele realizarse en el propio mercado a través de las Ofertas Públicas } \\
\text { de Adquisición de Acciones (OPA), asociadas a un mercado de } \\
\text { capital líquido, activo, sin barreras de entrada y eficiente [Fernández } \\
\text { Izquierdo et al, 2008: } 32 \text { ]. }\end{array}$ \\
\hline Alemán & $\begin{array}{l}\text { En este modelo, la concentración accionarial es muy importante. } \\
\text { Las empresas suelen estar controladas por grupos de inversores } \\
\text { estables con participaciones cruzadas o estructura piramidal. Estos } \\
\text { accionistas mayoritarios pasan a tener un protagonismo directo en } \\
\text { la gestión de la organización, los cuales buscan la viabilidad y la } \\
\text { rentabilidad de la empresa en el largo plazo. En este caso, los grupos } \\
\text { mayoritarios se consolidan y el mercado de capitales se vuelve } \\
\text { menos líquido, existiendo en ocasiones poderes de veto o blindajes } \\
\text { que obstaculizan las OPA, por tanto, la transferencia y control de } \\
\text { la propiedad se desarrolla, normalmente, entre los accionistas } \\
\text { significativos fuera del mercado. En cuanto al sistema legal, los } \\
\text { accionistas minoritarios de estos países tienen escasa protección de } \\
\text { sus derechos y además, es compleja de llevar la práctica [Fernández } \\
\text { Izquierdo et al, 2008: } 33 \text {. }\end{array}$ \\
\hline Japonés & $\begin{array}{l}\text { En Japón el sistema de gestión de las compañías y el sistema de } \\
\text { relaciones de en la estructura de propiedad está dominado por } \\
\text { los directivos de las empresas y se caracteriza por importantes } \\
\text { participaciones accionariales cruzadas entre las empresas. En Japón, } \\
\text { el típico consejo de administración está formado por } 21 \text { miembros, } \\
\text { casi todos son directivos de las mismas empresas. El presidente } \\
\text { del consejo es el primer ejecutivo. En cada compañía, tres o cuatro } \\
\text { directores, incluido el presidente gozan de derechos especiales para } \\
\text { representar a la empresa [Fernández Izquierdo et al, 2008: 34]. }\end{array}$ \\
\hline $\begin{array}{c}\text { Grupos } \\
\text { Económicos }\end{array}$ & $\begin{array}{l}\text { En los países iberoamericanos se han formado grupos económicos, } \\
\text { que los podemos caracterizar como una red de negocios donde un } \\
\text { conjunto de empresas es controlado por un número de accionistas } \\
\text { mayoritarios, usualmente miembros de una familia extendida o de } \\
\text { un círculo cerrado de asociados con nexos sociales. En estas redes de } \\
\text { negocios las empresas están conectadas entre sí mediante compañías } \\
\text { tenedoras de acciones e intercambios de representantes en los } \\
\text { consejos de administración [Chavarín, 2010: } 15] \text {. }\end{array}$ \\
\hline
\end{tabular}




\subsection{Caracterización de los Grupos Económicos}

Los grupos económicos - GE- son empresas familiares, esto es empresas en las que el control de una o dos familias es predominante, gracias a que el porcentaje de propiedad en manos de una de éstas es muy alto; a que la separación entre la propiedad y la gestión es marginal, no sólo de las tenedoras sino de prácticamente todas las filiales; a que la presencia de la familia en los consejos de administración sigue siendo determinante, y a que el reclutamiento de personal de más alto nivel da preferencia a miembros de ésta. Los valores patriarcales son muy fuertes y se expresan en toda la estructura organizacional de las grandes corporaciones, de tal suerte que es muy frecuente que el padre dirija los consejos de administración de la [o las] tenedoras más importantes, mientras los hijos encabezan los consejos de las filiales [Salas Porras, 2007: 310].

Los grandes grupos empresariales que dominan la actividad económica, tanto en México como en numerosos países del mundo, son mucho más que grupos estrictamente financieros y en gran medida diferentes a los agrupamientos monopolistas de capital presentes en los comienzos del s. XX en los países caracterizados por el control bancario sobre las actividades productivas y que tuvieron su expresión clásica en países como Alemania y Estados Unidos ${ }^{3}$

Los GE mexicanos son producto de un entorno en el que prevalece un estado de derecho limitado, el cual se caracteriza por un marco legal que no surge del consenso, un sistema de procuración de justicia deficiente y un conjunto de creencias y patrones culturales que dan pauta a la corrupción, al oportunismo y a una confianza social estrecha. La presencia de instituciones discrecionales [formales e informales], y el elevado costo que le generan a la actividad económica, propician la sustitución de los mecanismos de mercado por transacciones relacionadas [Castañeda, 2010: 603].

\footnotetext{
Cuando se habla de grupos de capital financiero por lo general se les ubica y define por su actividad y no por la organización del capital. La categoría "grupo de capital financiero" compete a la organización del capital, a su gestión, a sus formas de financiamiento privilegiadas en relación con el resto de las fracciones de capital, y a su propiedad y control. Es decir, a un conjunto de aspectos que forman parte de un proceso único y contradictorio de organización (Morera, 1998: 27).
} 


\subsection{Evolución de los grupos económicos en México: un proceso de centralización y concentración}

La existencia de grupos privados de capital financiero en México se remonta a la época de la dictadura del general Porfirio Díaz Mori ${ }^{4}$ Sin embargo, la relevancia en el proceso de acumulación de capital es un fenómeno mucho más reciente que se ubica a finales del decenio de los sesenta. A partir de entonces, las condiciones del proceso de concentración y centralización del capital cambiaron radicalmente, para convertirse de simple fracción predominante del capital privado nacional en agente principal del proceso de acumulación global del capital [Morera, 1998: 36-37].

En la evolución contemporánea de los grupos económicos podemos caracterizar cuatro grandes períodos: el primero que va de fines de los sesenta hasta 1982; otro período que abarca de 1983 a 1987; el siguiente abarca de 1988 a la crisis de 1994; y el último período inicia con la reorganización de las empresas producto de la crisis de 1994.

El primer período -que concluye en 1982- se caracterizó por un fuerte nacionalismo que, a través de leyes de mexicanización y restricciones comerciales, alentó la participación mayoritaria de capitales nacionales en la propiedad de las grandes empresas. Ejemplo de ello son la nacionalización de la industria minera en 1961, el decreto de 1962 que prohibía la importación de auto-partes y la Ley para regular la inversión extranjera de 1973 que limitaba la participación de capital extranjero en empresas de determinados sectores. Estas políticas hicieron posible el establecimiento de empresas de capital mixto y alianzas estratégicas entre empresas nacionales y extranjeras, como lo atestiguan el caso del Grupo Minera México en la industria de metales no ferrosos y del Grupo DESC, a través de su subsidiaria Spicer, en la industria automotriz [Castañeda, 2010: 607].

Entre 1982 y 2001, los bancos mexicanos han sufrido por lo menos tres veces cambios radicales en su estructura de propiedad: en 1982, José López Portillo estatiza la banca en medio de una crisis financiera

\footnotetext{
4 Porfirio Díaz Mori gobernó México de 1877 a 1911. Su gobierno se caracterizó por el orden y el progreso material. Aunque la terrible desigualdad imperante dio paso a la Revolución Social Mexicana de 1910 que terminó con su gobierno.
} 
y de pagos que ponía en una situación muy precaria a todo el sistema bancario. Como parte del paquete de las reformas económicas que Carlos de Salinas de Gortari promueve durante su gestión presidencial, se privatizan los bancos entre 1989 y 1992. Por último, ante la crisis bancaria que se inicia [o se agrava] con la devaluación de diciembre de 1994, el rescate bancario, la necesidad de intervenir algunos bancos por la descapitalización que representaba la cartera vencida, las muchas irregularidades y abusos en el manejo de créditos, las reformas en el sistema de regulación bancaria. Finalmente [de 1997 a 2001, con la adquisición por parte de la banca extranjera de una cantidad cada vez mayor de bancos], se producen nuevos reacomodos, ajustes, desarticulaciones y rearticulaciones en la red corporativa [Salas Porras, 2006 p. 333].

A partir de 1983, durante el régimen de Miguel de la Madrid ${ }^{5}$, comienza un proceso de recomposición de las relaciones económicas y políticas, que se centró, fundamentalmente, en la estructura de la propiedad del gran capital y en la restructuración del sistema financiero, cuyo aspecto más importante fue la redistribución de los recursos dinerarios dispersos hacia las actividades productivas internas. Todo ello fue posible debido a la profundidad de la crisis y a la impostergable necesidad de reestructurar el conjunto del capital [Morera, 1998: 41].

Producto de la estatización bancaria, las redes financieras de negocios perdieron a los bancos múltiples, que representaban el eje de su estructura de financiamiento y facilitaban las transferencias de flujos financieros entre sus distintas empresas. A su vez, entre los activos de la banca recién estatizada se encontraban una cantidad importante de acciones de empresas no financieras [desde hoteles hasta compañías manufactureras]; muchas de ellas eran de empresas relacionadas. En un principio esto significó que algunas redes de negocios perdieran segmentos completos de su estructura. Sin embargo, después se suavizaron

\footnotetext{
Miguel de la Madrid Hurtado fue Presidente de México del 1 de diciembre de 1982 al 30 de noviembre de 1988. Su administración estuvo caracterizada por una profunda crisis económica derivada de la caída del precio del petróleo y el aumento espectacular de la deuda externa durante los años 1981 y 1982. Tuvo que poner en marcha medidas de ajuste ordenadas por el Fondo Monetario Internacional como requisito para tener acceso al crédito externo. Inicia un proceso de apertura de la economía hacia el exterior y de liberalización en lo interno que habría de completar su sucesor Carlos Salinas de Gortari.
} 
algunas condiciones del decreto de expropiación, y en marzo de 1983, se reprivatizaron las empresas filiales de los bancos, lo que incluyó a todo el sector de las casas de bolsa y a las participaciones de empresas no financieras [Chavarín, 2010: 55].

Después de 1987, una vez saneados financieramente, los grupos económicos se enfrentaron a la imperiosa necesidad de cambiar su estructura productiva, para poder concurrir a los mercados nacional e internacional en condiciones de igualdad y competitividad. Esto era necesario no solamente porque la modalidad de los grandes grupos industriales internacionales está determinada por los mercados mundiales con sistemas de comercialización, abastecimiento y desarrollo tecnológico en escala internacional, sino también porque los cambios que se requerían enfrentaban una violenta competencia por recursos financieros y tecnológicos.

La reconversión de los grupos económicos mexicanos a su variante globalizada se ha dado a partir de estrategias muy diferentes. Por un lado, se encuentran los grupos que han seguido la estrategia tradicional de una transnacional con la que han logrado posicionarse como empresas dominantes en su ramo, ya sea mediante la creación de nuevas empresas en distintos países o la adquisición de compañías extranjeras establecidas. Una segunda estrategia es la de grupos que han buscado insertarse en la red global de producción, estableciendo una gran cantidad de alianzas estratégicas con empresas extranjeras. En ocasiones estas estrategias les han permitido incursionar en un mercado extranjero poco conocido y en otras adquirir tecnologías para participar como proveedores de empresas globales dominantes. Por último, se encuentran grupos diversificados con estrategias hibridas, las cuales varían dependiendo de la unidad de negocios en consideración [Castañeda, 2010: 613-614].

La crisis económica y un entorno internacional de mayor globalización han sido, bajo esta óptica, los catalizadores del cambio observado en las instituciones y en las estrategias empresariales. Estos factores hicieron que los tecnócratas promulgaran un conjunto de reformas a favor de la democracia, la apertura comercial, la desregulación, la competencia económica, la privatización de empresas paraestatales y la modernización del sistema financiero. Ante un entorno doméstico fuertemente recesivo e incierto los GE tuvieron, por primera vez, la 
motivación para impulsar, de manera coordinada, cambios en el sentido de una mayor competencia y transparencia. En el contexto de instituciones discrecionales dominadas por relaciones corporativistas, los GE generaban empresas de alta rentabilidad pero poca productividad. Ante la falta de capacidad exportadora, un magro ahorro agregado y poca capacidad tributaria, las crisis macroeconómicas dieron pauta a un reacomodo institucional de mayor apertura política y económica. En este nuevo entorno los grupos se vieron obligados a redirigir la expansión de sus negocios al mercado internacional [Castañeda, 2010: 612].

En este proceso de reacomodo han perdido muchos eslabones y aun cadenas productivas enteras que afirmaban los enlaces de la elite corporativa; por el otro, la información de mercados es más abundante y de mejor calidad. Además, cuando el mercado interno falla, se puede recurrir a los externos. La pérdida de cadenas completas y de eslabones de integración con el mercado interno hacen más difíciles los vínculos naturales entre empresarios nacionales con negocios integrados de manera vertical $u$ horizontal. La cantidad de empresas extranjeras que han asumido el control de industrias clave y obtienen el grueso de sus insumos en sus países de origen, tiende a disminuir también los puntos de contacto y las antiguas plataformas estratégicas para los negocios de la elite corporativa [Salas Porras, 2006: 370].

\subsection{El gobierno corporativo de los Grupos Económicos}

En México, no obstante existe otra configuración del accionariado de las principales empresas del país ya que están integradas en los llamados "grupos económicos". El control ejercido por el bloque compacto de accionistas es uno de los rasgos principales que distinguen a los grupos económicos de los grandes conglomerados anglosajones. A lo largo del s. XX esta estructura de control se mantuvo, independientemente de que los grupos evolucionaron del esquema prerrevolucionario al posrevolucionario y de este último al globalizado. Hoy en día el bloque de accionistas retiene el control a través de diversos mecanismos: acciones controladoras, piramidación de empresas, fideicomisos, acciones con derechos de voto limitado, acciones con restricción de tenencia, certificados de participación ordinaria y empaquetamiento de acciones [Castañeda, 2010: 623]. 
En Latinoamérica, el principal problema de agencia surge entre los accionistas mayoritarios y los minoritarios. Como resultado, los primeros se benefician a costa de los segundos a través de la expropiación, el nepotismo y la corrupción política. En efecto, la raíz de este problema surge de dos fuentes: la estructura de gobierno corporativo de las compañías negociadas públicamente en la bolsa pública aísla a los grandes accionistas de las amenazas de tomas de control y los monitoreos; y el sistema legal no protege a los accionistas minoritarios porque las leyes son insuficientes o porque no se ejercen.

López de Silanes [2009:77-78] defiende la existencia de una relación entre el gobierno corporativo y ciertos rasgos del mercado de capitales. En esencia, encuentra que el ordenamiento jurídico y la aplicación de las leyes, en lo que concierne a la protección del accionista minoritario tiene repercusiones muy claras sobre: a. La participación de inversionistas minoritarios [inversores con participaciones de menos del 10\%] en los mercados de capitales; b. La concentración de la propiedad [concentración que retroalimenta la renuencia del accionista minoritario a participar en el capital], y c. La extensión y profundidad de los mercados de capitales.

Las razones por las que el accionista minoritario potencial sería renuente a participar en el capital de empresas con la propiedad concentrada se pueden resumir en dos grandes grupos: 1. Los "derechos anti-director" [sintetizados en un "índice de derechos anti-director"], es decir, las posibilidades que tiene el accionista minoritario de influir sobre el gerente [valor alto del índice] o el grado con que el ordenamiento jurídico tolera que el gerente pueda atrincherarse frente a la voz y al voto del accionista minoritario [valor bajo del índice]; 2 . La protección jurídica frente al auto-negocio [self-dealing]. El self-dealing es el principal problema de gobierno coporativo. Naturalmente, si la legislación y su aplicación no protegen al accionista minoritario, éste está en riesgo permanente de ser saqueado, sea por los gerentes, sea por los accionistas mayoritarios.

México ha modificado su legislación para tratar de defender los intereses de los accionistas minoritarios. Una de las reformas legales más importantes ha sido la adopción de un subtipo societario con un estatuto específico para las sociedades anónimas que cotizan en la Bolsa Mexicana de Valores sin ser entidades financieras: la Sociedad 
Anónima Bursátil [=SAB]. Esta nueva figura se incluye en la Ley del Mercado de Valores [LMV] de 2006 en los artículos 22 a 57 de la LMV se regula la denominación social; la administración; los deberes de diligencia y lealtad; las acciones de responsabilidad; la vigilancia; la gestión y la ejecución de negocios sociales; la asamblea de accionistas; los derechos de los socios; la emisión de acciones; y, las operaciones sobre los títulos acciones. Hasta antes de la entrada en vigor de la nueva LMV de 2006, la regulación bursátil se circunscribía a los diversos actores del mercado de valores [intermediarios, bolsa de valores, títulos], pero no a las sociedades no financieras emisoras de los títulos acciones, a las que si bien se imponían requisitos para cotizar en la Bolsa, no se regulaba su estructura interna. El enfoque siempre fue la debida protección del mercado y del público inversionista [Guadarrama López, 2008: 9-10].

Los accionistas mayoritarios emplean diferentes mecanismos para mantener el control, por ejemplo: empleándose en la gerencia alta, sirviendo en el Consejo de Administración, limitando el intercambio de acciones y/o formando grupos de empresarios. En el caso mexicano, de las compañías que cotizan en la Bolsa de Valores de Nueva York, el 44\% tienen un grupo de accionistas con una participación mayoritaria en la firma [Santiago et al, 2009: 29].

En cuanto a la administración, los GE tienen un núcleo relativamente reducido de administradores que tienen muchas relaciones entre sí y con todos los demás, y que hay una periferia de administradores que tienen relaciones más raras con todos los demás. La centralización mide la asimetría entre un núcleo de nodos y todos los demás, esto es, si existen unos pocos nodos que concentran gran parte del mundo relacional de la red, entonces decimos que la red está centralizada.

Otro dato de interés es el alto coeficiente de clustering, que, para un nodo, es la densidad de su ego-red abierta [ego-red abierta es la formada por todos sus vecinos exceptuándose a sí mismo]. El coeficiente de clustering para toda la red es la media de los coeficientes de cada nodo, y para el coeficiente ponderado se pondera cada nodo por su grado. Es normal que el coeficiente de clustering sea alto para la red de administradores, ya que la estructura de la red de afiliación consiste en la interconexión de los clústeres que en realidad forman los propios Consejos. Pero también es alto el coeficiente de clustering de la red de empresas, que no tiene esta característica básica. Para la red de accionistas 
de control, ya el coeficiente dicotómico es mucho más bajo, reflejando el fraccionamiento de los inversores específicamente de control [Santos y Arcudia, 2010: 11].

En síntesis, el gobierno empresarial en México se caracterizan por: a. Unas configuraciones de red tipo "grupo empresarial" donde una familia [a veces, menos], o una alianza de familias, detenta participaciones de control "absoluto" de las empresas. Este control familiar se ve reforzado por las series de acciones que se reservan el control; $b$. Insignificancia de las configuraciones tipo "capitalismo financiero", "gerencialista" y "de inversores"; y, c. Sobre la red de administradores en conjunto, podemos decir que es muy densa, cercana y está muy centralizada, es decir, que a pesar de estar formada por grupos empresariales relativamente arracimados y exclusivos, se encuentran entre ellos como formando una más amplia trama donde se interrelacionan densa y centralizadamente. Como si, reservándose particularmente el control de sus empresas-tipo-familiar, buscaran un control colectivo del espacio económico [Santos y Arcudia, 2012: 20].

\section{Los deberes delealtad y de diligencia delosadministradores en el gobierno corporativo}

Larrea Martínez y Vargas García [2009: 23] sostienen que la sociedad anónima es la entidad social más avanzada de gobierno corporativo. En México, el gobierno corporativo ha tenido su mayor difusión en la sociedad anónima, en la sociedad anónima bursátil y la sociedad de inversión, regulados en la Ley del Mercado de Valores -LMV.

Siguiendo a los autores arriba señalados, las medidas que propone el Gobierno Corporativo se pueden agrupar en tres grandes bloques:

- Medidas para la elección de la forma social

- Medidas internas a la corporación: reconocimiento de derechos y obligaciones de los sujetos; y, determinación de la estructura y organización para la administración y procedimiento de control

- Medidas de control externo a la corporación: prácticas de prevención y disminución del riesgo; prácticas de transparencia; prácticas de competencia; y, prácticas sobre la sucesión y permanencia de los miembros de la corporación. [Larrea y Vargas, 2009: 24-27] 
Para la extensión del presente trabajo resultaría inacabable analizar las tres clases de medidas de Gobierno Corporativo sintetizadas líneas arriba. Dada la centralización y concentración del poder de los grupos económicos mexicanos en unos cuantos accionistas que a su vez son administradores, consideramos de capital importancia analizar el agravamiento de los deberes fiduciarios de lealtad y de diligencia, así como su exigibilidad por medio de acción judicial.

\subsection{El Cadbury's Report}

En el contexto extranjero el Cadbury's Report pone el acento en los aspectos estructurales y funcionales del órgano de administración, superando, por la sofisticación que propone al respecto, la cuestión de los modelos monistas y dualistas, los ponen, en cambio, el acento en los deberes de los administradores. Los deberes principales son: el deber de diligencia [duty of care] y el de fidelidad [duty offair dealing]. Si el deber de diligencia se nutre del principio del correcto juicio empresarial [business judgement rule], los deberes de fidelidad se pueden tipificar más ajustadamente.

Así, en el apartado 5.01 de los Principles of Corporate Governance; Analysis and Recomendations del American Law Institute se afronta la cuestión en general de los conflictos de intereses de los administradores y el género de conducta transparente que deben observar éstos en esos casos; el apartado 5.02, concreta más, y se ocupa de las transacciones entre los administradores y la sociedad y de las necesarias autorizaciones al respecto; el apartado 5.03 se ocupa de las circunstancias en que la remuneración que obtengan los administradores por los contratos de servicios que concierten con la sociedad no vulnera los deberes fiduciarios; el apartado 5.04 contempla el uso que pueden realizar los administradores de los activos de la empresa, de la información reservada y de su posición en la compañía; el apartado 5.05 se ocupa de las oportunidades de negocio y del modo de afrontarlas; el apartado 5.06 contempla la obligación de no competencia y los supuestos en que puede exceptuarse, etc. [Bisbal I Méndez, 1997: 1693].

\subsection{Los principios de gobierno corporativo de la OCDE}

La OCDE adoptó en 1999 sus "Principios de Gobierno Corporativo" con el carácter de no obligatorio. Estos principios constituyen un referente 
común para los diversos involucrados con aspectos de gobierno corporativo; miembros de la academia, elaboradores de leyes y los diferentes miembros de las empresas, directores, administradores, entre otros. Los Principios recogen algunas experiencias de empresas cotizadas en mercados internacionales por regiones en donde se encontraron deficiencias y recomendaciones comunes. La aportación sustantiva de los principios de gobierno corporarativo de la OCDE incluye, entre otros, el esfuerzo internacional por encontrar lineamientos que contribuyan a la mejora de la empresa [Larrea y Vargas, 2009: 10]

En el apartado VI de los Principios de la OCDE -relativo a las responsabilidades del Consejo de Administración- se establece en los literales A y C que:
A. Los miembros del Consejo deberán actuar disponiendo siem- pre de la información más completa, de buena fe, con la diligencia y atención debidas y en el más alto interés de la sociedad y de los accionistas. [...]
C. El Consejo deberá aplicar unos niveles de ética muy elevados. Deberá tener siempre en cuenta los intereses de las partes intere- sadas [...] [OCDE, 2004: 60 y 61]

\subsection{El código de mejores prácticas corporativas del Consejo Coordinador Empresarial de México}

En el punto relacionado con el desarrollo normativo del Gobierno Corporativo en México podemos apuntar dos grandes hitos. El primero de ellos es el Código de Mejores Prácticas Corporativas del Consejo Coordinador Empresarial, organismo que agrupa a las asociaciones de empresarios del país. En este Código se contienen una serie de recomendaciones para dar trasparencia a la toma de decisiones en las grandes corporaciones. Sus medidas van destinadas a la información en la Asamblea de Accionistas; a la composición y funcionamiento del Consejo de Administración; función de auditoría del Comité de Auditoría del Consejo de Administración; funciones de compensación y evaluación de los directivos por parte del Consejo de Administración; así como las funciones de finanzas y planeación de la administración societaria. El segundo de ellos es la incorporación de sus previsiones al texto de la LMV en 2005, como veremos más adelante. 
En la exposición de motivos del Código de Mejores Prácticas se expresa que para que los interesados tengan confianza en el manejo de las empresas, es necesario que éstas cuenten con transparencia en su administración y se fomente una adecuada revelación de la información a los interesados. En dicho código se establecen recomendaciones de aplicación voluntaria en un primer momento de la puesta en marcha de una empresa, para mejorar su gobierno corporativo. El código puede aplicarse a todas las empresas mexicanas, ya sean cotizadas en bolsa o no, reconociendo que existen ciertos principios que solamente regirían a las cotizadas en bolsa, por la propia naturaleza de éstas. [García Velasco, 2005: 63-64]

En la sección IV.5 el Código de Mejores Prácticas entiende que los consejeros asumen obligaciones y responsabilidades al aceptar su cargo; el desconocimiento de las mismas no los exime de sus deberes fiduciarios de lealtad y de diligencia, por lo que resulta importante que conozcan el alcance y las implicaciones legales, así como estatutarias de sus funciones. [Consejo Coordinador Empresarial, 2010: 20]

La sección en comento tiene dos prácticas recomendadas la 21 , relativa a la información que deben recibir los consejeros; y, la práctica 22 en la que se recomiendan medidas tendientes a evitar faltas a los deberes de lealtad y de diligencia.

Práctica 21.

Se recomienda que a cada consejero se le proporcione la información necesaria, respecto a las obligaciones, responsabilidades y facultades que implica ser miembro del Consejo de Administración de la sociedad. [Consejo Coordinador Empresarial, 2010: 20]

Práctica 22.

Para el mejor cumplimiento de los deberes fiduciarios y las responsabilidades de los consejeros, se recomienda atender a lo siguiente:

I. Comunicar al Presidente y a los demás miembros del Consejo de Administración, cualquier situación en la que exista o pueda derivarse en un conflicto de interés, absteniéndose de participar en la deliberación correspondiente.

II. Utilizar los activos o servicios de la sociedad solamente para el cumplimiento del objeto social y tener definidas 
políticas claras que permitan, en casos de excepción, utilizar dichos activos para cuestiones personales.

III. Dedicar a su función el tiempo y la atención necesaria, asistiendo como mínimo al $70 \%$ de las reuniones a las que sea convocado durante el año.

IV. Mantener absoluta confidencialidad sobre toda la información que reciban con motivo del desempeño de sus funciones y, en especial, sobre su propia participación y la de otros consejeros, en las deliberaciones que se lleven a cabo en las sesiones del Consejo de Administración.

V. Los consejeros propietarios y, en su caso, sus respectivos suplentes deberán mantenerse mutuamente informados acerca de los asuntos tratados en las sesiones del Consejo de Administración a las que asistan.

VI. Apoyar al Consejo de Administración con opiniones y recomendaciones que se deriven del análisis del desempeño de la empresa, con objeto de que las decisiones que adopte se encuentren debidamente sustentadas.

VII. Establecer un mecanismo de evaluación del desempeño y cumplimiento de las responsabilidades y deberes fiduciarios de los consejeros [Consejo Coordinador Empresarial, 2010: 21].

\subsection{La Ley del mercado de valores}

La Ley del Mercado de Valores -LMV- trata de regular a los grupos económicos introduciendo en su articulado la definición de grupo empresarial como:

El conjunto de personas morales organizadas bajo esquemas de participación directa o indirecta del capital social, en las que una misma sociedad mantiene el control de dichas personas morales. Asimismo, se considerarán como grupo empresarial a los grupos financieros constituidos conforme a la Ley para Regular las Agrupaciones Financieras [Artículo 2 fracción X LMV].

Esta definición es trascendente puesto que la LMV impone restricciones a empresas, administradores y empleados que pertenezcan al 
mismo grupo empresarial. Prevé la posibilidad legal de la constitución de tres nuevas clases de sociedades mercantiles: la Sociedad Anónima Bursátil [SAB]); la Sociedad Anónima Promotora de Inversión Bursátil; y la Sociedad Anónima Promotora de Inversión. Dichas sociedades se suman a las ya previstas en la Ley General de Sociedades Mercantiles y demás leyes especiales.

La SAB es un subtipo societario [exposición de motivos de la LMV] se incorpora un estatuto jurídico específico para las anónimas que sin ser entidades financieras cotizan en la BMV. Así, la ley incluye un amplio capítulo para la SAB [arts. 22 al 57], en el que se regula la denominación social, la administración, los deberes de diligencia y lealtad, las acciones de responsabilidad, la vigilancia, la gestión y ejecución de negocios sociales, la asamblea de accionistas, los derechos de los socios, la emisión de acciones y las operaciones sobre los títulos de acciones [Guadarrama, 2008: 7-10].

La administración de la SAB estará a cargo de un consejo de administración compuesto por un máximo de veintiún consejeros, de los cuales, cuando menos, el veinticinco por ciento deberán ser independientes [artículo $24 \mathrm{LMV}$ ]. La inclusión de los deberes fiduciarios de diligencia y de lealtad de los administradores de la SAB en la LMV constituye un paso significativo en la recepción formal de la jurisprudencia del common law en materia de directivos de las sociedades mercantiles [duty of loyalty and duty of care; Nava, 2006: 532]

\section{Los deberes delealtad yde diligencia delosadministradores de las sociedades anónimas}

Corresponde a los administradores la gestión y representación de la sociedad. La administración social viene entendida en general de una manera amplia que comprende la realización de un conjunto de actos, de diversa naturaleza, tendientes a la consecución del objeto social. En este sentido resulta claro que se confiere a los administradores competencias sobre asuntos de una cierta complejidad, siendo el mismo concepto de administración una noción amplia e indeterminada. El órgano dedicado a la administración de la sociedad es necesario, precisamente por tener conferida la gestión y la representación de la sociedad. Su actuación es precisa para la realización del objeto social, que implica 
una actividad que por regla general es el ejercicio de una actividad empresarial, que en gran medida depende de la labor de los administradores. Pero al propio tiempo han de ocuparse de la organización de la sociedad, de su relación con los accionistas y del funcionamiento de los demás órganos de la sociedad [Sánchez Calero, 2008: 470].

\subsection{Regulación de los deberes de los administradores de la sociedad anónima en la Ley General de Sociedades Mercantiles}

La sociedad anónima mexicana ha tenido cierta evolución a pesar de que se carecía de reformas sustanciales a la Ley General de Sociedades Mercantiles de 1934 desde su creación. Los legisladores mexicanos han extraído de la experiencia internacional conceptos importantes para los regímenes de la sociedad anónima; es decir, de las variaciones de dicha sociedad en otras leyes que rigen áreas diferentes de la actividad económica: sociedades de construcción inicial como la sociedad anónima, pero con particularidades.

El artículo 157 de la LGSM establece que los administradores tendrán las responsabilidades inherentes a su mandato y la derivada de las obligaciones que la ley y los estatutos le imponen. Así las cosas, la regulación genérica de los deberes de los administradores puede ser pactada o bien establecida en la ley.

Según el artículo 147 de la LGSM los administradores deben desempeñar personalmente su cargo. Por mandato del artículo 160 de la LGSM deben denunciar por escrito a los comisarios cualquier irregularidad de la cual tengan conocimiento, cometida por sus antecesores.

El artículo 156 de la LGSM norma el deber de lealtad estableciendo que el administrador que tenga un interés opuesto a la sociedad debe manifestarlo y abstenerse de votarlo. Considera interés opuesto un interés personal en el negocio; competencia del administrador en lo personal, con la sociedad; $y$, aprovechamiento personal de las oportunidades de negocio de la sociedad.

Para el supuesto de que un administrador con interés opuesto votara, su voto se considerará válido pero responderá por daños y perjuicios.

La LGSM guarda silencio sobre la regla del juicio de los negocios -que veremos más adelante- o sobre el deber de diligencia. 
Como tendremos de analizar en los subsiguientes apartados, la LMV vino a complementar la regulación de la LGSM en materia de deberes fiduciarios de diligencia y de lealtad.

\subsection{Deber de diligencia}

El deber de diligencia tiene la función primordial de evitar que los administradores gestionen negligentemente la empresa, prefiriendo dedicar más tiempo a sus intereses personales en perjuicio de su dedicación al cargo de administrador; en el contexto de conflictividad en materia de intereses que envuelve el ejercicio de su cargo [Galindo, 2007, 270].

El deber de diligencia de los administradores consiste fundamentalmente en que deben de actuar de buena fe y en el mejor interés de la sociedad y no para atender el interés de una persona en lo particular. Esto es, debe terminarse con la vieja costumbre de nombrar consejeros que protejan los intereses de un accionista. La regulación de la LMV obliga a los consejeros a solicitar y analizar la información de la sociedad sobre aquellos aspectos críticos relevantes, en los cuales pudiera radicar la oportunidad de mayores eficiencias o minimizar riesgos. Igualmente deben requerir la presencia de directivos relevantes y demás personas de apoyo, a efecto de entender claramente las circunstancias que imperan en las organizaciones a las que sirven. Por ningún motivo debe aceptarse la decisión de los demás sin haber estado enterado o recibir información previa o suficiente sobre el punto de discusión [Cruz Reyes, 2006: 31].

Los consejeros que no asistan a las juntas del consejo de administración incurren en una falta relevante al deber de diligencia. También es crítico que durante las reuniones del consejo de administración sus miembros no revelen información relevante necesaria para la adecuada toma de decisiones [Cruz Reyes, 2006: 32].

La doctrina ha asociado al deber de diligencia la regla del juicio de los negocios, conocida como el Business Judgement Rule. La doctrina anglosajona ha establecido cuatro condiciones generales para la regla del juicio de los negocios:

a. Debe existir una decisión: por ejemplo, no realizar una pregunta necesaria o cualquier otra falla al ejecutar una acción, no justifica la protección bajo esta regla. 
b. Existe un deber de informarse en relación con el juicio de negocio de manera que razonablemente se considere apropiado bajo las circunstancias.

c. La decisión debió realizarse de buena fe, de manera que la condición no se satisface si el comerciante sabe que violó la ley.

d. No deberá existir un interés financiero en el objeto principal de la decisión. Por ejemplo, la regla del juicio de los negocios no es aplicable para probar su propiedad [Larrea y Vargas, 2009: 88-89]

Así las cosas, esta obligación fiduciaria de los administradores fue caracterizada por los tribunales norteamericanos en dos casos: Kamin vs. American Express Company y en Brehm vs. Eisner. En el primero de ellos La corte de Nueva York estableció que los tribunales no deben interferir en cuestiones relativas al criterio de los negocios del Consejo de Administración a menos que se presente alguno de los siguientes elementos: fraude, ilegalidad, colusión, propósito deshonesto [Nava, 2006: 532-533].

En Brehm vs. Eisner; un litigio en el cual el demandante pidió responsabilidad del antiguo y del nuevo Consejo de Administración de Disney por incurrir en incumplimiento del deber de diligencia al contratar y rescindir anticipadamente el contrato del Presidente de la Compañía, respectivamente. Por lo que hace a la contratación del Presidente de la compañía, la Corte de Delawere resolvió que el antiguo consejo de administración se condujo con suficiente cuidado al contratar a un experto calificado y escuchar su opinión antes de aprobar el contrato de empleo del nuevo Presidente corporativo. Por lo que respecta a la recisión anticipada de su contrato por parte del nuevo consejo de administración de Disney, ésta fue una adecuada decisión de negocios que le evitó a la compañía un costoso litigio, así como la distracción de recursos humanos y materiales, mala publicidad y pérdida de costos de oportunidad. Ante la ausencia de fraude o mala fe de parte de los consejeros, el solo desacuerdo del actor con la decisión tomada no fue suficiente para acreditar la responsabilidad de los directivos por presunta violación del deber de diligencia [Nava, 2006: 534-536].

Por lo que respecta a la legislación mexicana, nuestra LMV establece que los miembros del consejo de administración, en el ejercicio diligente de las funciones que la LMV y los estatutos sociales le con- 
Gobierno corporativo y grupos económicos en México: especial referencia...

fieran a dicho órgano social, deberán actuar de buena fe y en el mejor interés de la sociedad y personas morales que ésta controle, para lo cual podrán:

I. Solicitar información de la sociedad y personas morales que ésta controle, que sea razonablemente necesaria para la toma de decisiones. Al efecto, el consejo de administración de la sociedad podrá establecer, con la previa opinión del comité que desempeñe las funciones en materia de auditoría, lineamientos que establezcan la forma en que se harán dichas solicitudes y, en su caso, el alcance de las propias solicitudes de información por parte de los consejeros.

II. Requerir la presencia de directivos relevantes y demás personas, incluyendo auditores externos, que puedan contribuir o aportar elementos para la toma de decisiones en las sesiones del consejo.

III. Aplazar las sesiones del consejo de administración, cuando un consejero no haya sido convocado o ello no hubiere sido en tiempo o, en su caso, por no habérsele proporcionado la información entregada a los demás consejeros. Dicho aplazamiento será hasta por tres días naturales, pudiendo sesionar el consejo sin necesidad de nueva convocatoria, siempre que se haya subsanado la deficiencia.

IV. Deliberar y votar, solicitando se encuentren presentes, si así lo desean, exclusivamente los miembros y el secretario del consejo de administración. [Artículo 30 LMV]

Los preceptos anteriores, dan instrumentos de información a los miembros del consejo de administración para que conozcan el alcance de sus decisiones. No obstante lo anterior, la LMV prevé casos específicos de las faltas al deber de diligencia reduciendo la ambigüedad existente sobre el término [Larrea y Vargas, 2009: 94]. Así las cosas, los miembros del consejo de administración de las SAB faltarán al deber de diligencia y serán susceptibles de responsabilidad en términos de lo establecido en el artículo 33 de la LMV, cuando causen un daño patrimonial a la sociedad o a las personas morales que ésta controle o en las que tenga una influencia significativa, en virtud de actualizarse alguno de los supuestos siguientes: 
I. Se abstengan de asistir, salvo causa justificada a juicio de la asamblea de accionistas, a las sesiones del consejo y, en su caso, comités de los que formen parte, y que con motivo de su inasistencia no pueda sesionar legalmente el órgano de que se trate.

II. No revelen al consejo de administración o, en su caso, a los comités de los que formen parte, información relevante que conozcan y que sea necesaria para la adecuada toma de decisiones en dichos órganos sociales, salvo que se encuentren obligados legal o contractualmente a guardar secreto o confidencialidad al respecto.

III. Incumplan los deberes que les impone la LMV o los estatutos sociales de la sociedad [Artículo 32 de la LMV].

En términos generales el deber de diligencia puede traducirse en una obligación de tomar decisiones de manera informada. Para allegarse de esa información los consejeros deberán solicitarla a los funcionarios sociales y no podrán renunciar a participar en las deliberaciones y votaciones; salvo que tengan algún impedimento. La regla de juicio del negocio limita su deber de diligencia. Asimismo como hemos visto en la jurisprudencia extranjera limita la acción de responsabilidad a los casos de fraude, colusión, ilegalidad o propósito deshonesto; y aun cuando la decisión pueda resultar onerosa a la sociedad, si se tomó de forma informada, exculpa de responsabilidad a los administradores. Este deber se ve complementado con el deber de lealtad que analizaremos a continuación.

\subsection{Deber de lealtad}

El deber de lealtad persigue con carácter general que los administradores no antepongan la consecución de su interés personal a la consecución del interés social; es decir se abstengan de obtener cualquier beneficio personal a expensas de la sociedad. También se define como la obligación de los directivos y los accionistas controladores o mayoritarios de comportarse con inherente ánimo previsor, justo y escrupuloso en aquellos asuntos en los que directa o indirectamente pudieran recibir algún beneficio, es decir, en aquellos casos en los que pudiera presentarse un conflicto de intereses [Galindo, 2007: 270-271]. 
En cuanto a este deber el caso Bayer vs. Beran es un clásico del derecho corporativo norteamericano que ilustra la observancia del deber de diligencia de los administradores para con los intereses sociales. En el caso de referencia el actor demandó a los directivos de Celanese Corporation of America por presunta negligencia y malversación al embarcar a la compañía en la contratación de un programa de radio amenizado por una cantante que a la sazón era la esposa del presidente de Celanese [la señora Dreyfus]. Para la corte de Nueva York no existió evidencia suficiente para acreditar que el programa de radio fuera diseñado con el propósito de impulsar la carrera artística de la señora Dreyfus, cuya calidad artística estaba fuera de duda. Además la Corte concluyó que el pago realizado era comparable al que imperaba en el mercado artístico en el momento de la contratación.

En adición a ello, la Corte Suprema de Nueva York encontró que los directores actuaron honestamente en todo momento en el libre ejercicio de su sano juicio de negocios y que su conducta no constituyó negligencia, malversación o imprevisión, pues cumplieron con las formalidades exigidas para la toma de esta clase de decisiones [Nava, 2006: 538-539].

En el ordenamiento jurídico mexicano, a fin de cumplir con su deber de lealtad, los miembros del consejo de administración deberán realizar las siguientes conductas:

Los miembros y secretario del consejo de administración de las sociedades anónimas bursátiles, deberán guardar confidencialidad respecto de la información y los asuntos que tengan conocimiento con motivo de su cargo en la sociedad, cuando dicha información o asuntos no sean de carácter público [Artículo 34 de la LMV].

Los miembros y, en su caso, el secretario del consejo de administración, que tengan conflicto de interés en algún asunto, deberán abstenerse de participar y estar presentes en la deliberación y votación de dicho asunto, sin que ello afecte el quórum requerido para la instalación del citado consejo [Artículo 34 de la LMV] ${ }^{6}$.

\footnotetext{
${ }^{6}$ No obstante que la LMV señala conductas asociadas con la deslealtad, la característica fundamental es que deben existir beneficios económicos para sí o a favor de terceros en el género.
} 
Ahora bien, la LMV no se limita a establecer la generalidad de este principio sino que establece casos específicos en el artículo 35 establece que los miembros del consejo de administración incurrirán en deslealtad frente a la sociedad o personas morales que ésta controle o en las que tenga una influencia significativa, siendo responsables de los daños y perjuicios causados a éstas o aquélla, cuando realicen cualquiera de las conductas siguientes:

I. Voten en las sesiones del consejo de administración o tomen determinaciones relacionadas con el patrimonio de la sociedad o personas morales que ésta controle o en las que tenga influencia significativa, con conflicto de interés.

II. No revelen, en los asuntos que se traten en las sesiones del consejo de administración o comités de los que formen parte, los conflictos de interés que tengan respecto de la sociedad o personas morales que ésta controle o en las que tengan una influencia significativa. Al efecto, los consejeros deberán especificar los detalles del conflicto de interés, a menos que se encuentren obligados legal o contractualmente a guardar secreto o confidencialidad al respecto.

III. Favorezcan, a sabiendas, a un determinado accionista o grupo de accionistas de la sociedad o de las personas morales que ésta controle o en las que tenga una influencia significativa, en detrimento o perjuicio de los demás accionistas.

IV. Aprueben las operaciones que celebren la sociedad o las personas morales que ésta controle o en las que tenga influencia significativa, con personas relacionadas, sin ajustarse o dar cumplimiento a los requisitos que esta Ley establece.

V. Aprovechen para sí o aprueben en favor de terceros, el uso o goce de los bienes que formen parte del patrimonio de la sociedad o personas morales que ésta controle, en contravención de las políticas aprobadas por el consejo de administración.

VI. Hagan uso indebido de información relevante que no sea del conocimiento público, relativa a la sociedad o personas morales que ésta controle o en las que tenga influencia significativa.

VII. Aprovechen o exploten, en beneficio propio o en favor de terceros, sin la dispensa del consejo de administración, oportunidades de 
Gobierno corporativo y grupos económicos en México: especial referencia...

negocio que correspondan a la sociedad o personas morales que ésta controle o en las que tenga influencia significativa ${ }^{7}$.

Si el deber de diligencia impone a los administradores la obligación de informarse y participar; el de lealtad impide divulgar información confidencial y abstenerse de participar en caso de conflicto de intereses. La jurisprudencia norteamericana limita este deber incluso para el caso de que pueda existir un presunto conflicto de intereses a que se haya actuado de mala fe.

\subsection{Acción de responsabilidad}

Para que estos deberes no queden en una mera declaración de buenas intenciones, la LMV provee a la SAB y a sus accionistas de una acción por responsabilidad contra el consejo de administración, por haber faltado al deber de diligencia o al de lealtad.

La LMV establece que podrá ejercerlo la propia SAB o los accionistas que representen por lo menos el $5 \%$ del capital social. El demandante podrá transigir en juicio el monto de la indemnización por daños y perjuicios siempre que previamente lo someta a la aprobación del consejo de administración de la sociedad. La falta de dicha formalidad será causa de nulidad relativa [artículo 38 de la LMV].

Las acciones de responsabilidad prescriben en cinco años contados a partir del día en que se hubiere realizado el acto o hecho. Las personas que a juicio del juez hayan ejercido la acción con temeridad o mala fe, serán condenadas al pago de costas.

\footnotetext{
$\mathrm{Al}$ efecto, se considerará, salvo prueba en contrario, que se aprovecha o explota una oportunidad de negocio que corresponde a la sociedad o personas morales que ésta controle o en las que tenga una influencia significativa, cuando el consejero, directa o indirectamente, realice actividades que: a) Sean del giro ordinario o habitual de la propia sociedad o de las personas morales que ésta controle o en las que tenga una influencia significativa. b) Impliquen la celebración de una operación o una oportunidad de negocio que originalmente sea dirigida a la sociedad o personas morales citadas en el inciso anterior. c) Involucren o pretendan involucrar en proyectos comerciales o de negocios a desarrollar por la sociedad o las personas morales citadas en el inciso a) anterior, siempre que el consejero haya tenido conocimiento previo de ello. (Artículo 35 de la LMV)
} 
En general, la LMV imputa a los miembros del consejo y su secretario, al pago de todos los gastos y costos que se originen del desempeño de sus responsabilidades, siempre que la autoridad judicial así lo dictamine.

Respecto de las sanciones de carácter penal se prevé prisión de tres a doce años a los consejeros, directores generales, directivos relevantes y empleados que, con ánimo de lucro, perjudiquen a los accionistas alterando las cuentas o condiciones de contratos, haciendo aparecer operaciones o gastos inexistentes o exagerando los reales, o bien, que a sabiendas realicen cualquier acto u operación perjudicial al patrimonio de la sociedad. De dos a diez años de prisión a quienes lleven oferta pública de valores no inscritos en el Registro Nacional de Valores sin contar con la autorización de la Comisión Nacional Bancaria y de Valores. Por último de tres a nueve años a los miembros del consejo, directivos o empleados que den noticias o información a terceros sobre las operaciones, servicios o depósitos sin instrucción expresa de los titulares o de las autoridades facultadas [Artículos 375-377 de la LMV].

\section{Conclusiones}

El movimiento del Gobierno Corporativo ha propugnado por la implementación de una serie de medidas para tratar de gobernar dirigir y monitorear las grandes sociedades. Estas medidas son necesarias porque en las grandes sociedades se presentan agency problems que enfrentan a los accionistas entre sí; o a los accionistas con los administradores. En el presente trabajo analizamos medidas internas de la corporación que tienden a regular los deberes de los administradores para con la sociedad y los socios: el deber de diligencia y el de lealtad.

La forma predominante de arquitectura organizacional y gobierno corporativo de las empresas mexicanas constituyen grupos económicos. No obstante los GE conviven con empresas organizadas de otra manera. Entendemos por éstos una red de empresas controladas por una sola familia o gente de un círculo social muy estrecho. Generalmente el control se ejerce por participación accionarial y por consejeros múltiples. Los otros modelos de gobierno corporativo contemplan accionariado disperso, control por parte de inversores institucionales, cuyo objetivo es únicamente económico, y control de los propios 
gestores. La forma de grupo económico obedece a múltiples factores como un entorno legal débil, o inseguridad para ejercer las transacciones en el mercado.

Los grupos económicos, si bien datan del Porfiriato, han experimentado fuertes recomposiciones en la última parte del s. XX y en lo que va del presente siglo. A partir de 1982, con la quiebra del modelo económico en el que el Estado era el eje articulador de la economía, comienzan a ser ellos el principal instrumento de centralización de los recursos. Durante la década de los 80 se reorganizan a partir de la estatización bancaria. Su proceso de recomposición comienza con la devolución de los activos no bancarios y la reprivatización de las casas de Bolsa. Otra etapa de la reconfiguración se abre con la reprivatización bancaria y la venta de las empresas del Estado en el sexenio de Carlos Salinas de Gortari. Finalmente la crisis de 1994-1995 obliga a otra reorganización de los GE hacia el exterior.

Los deberes de lealtad y de diligencia han sido regulados extensamente por la LMV y son aplicables a las sociedades anónimas que cotizan en la Bolsa Mexicana de Valores, las SAB. La regulación proviene del derecho anglosajón y para una mejor comprensión es menester analizar la jurisprudencia Norteamericana. En términos generales el deber de diligencia consiste en participar de manera informada en la toma de decisiones sociales; y el de lealtad no divulgar información privilegiada o confidencial y abstenerse de participar en caso de conflicto de intereses. La acción por responsabilidad está limitada por la regla del juicio de negocio y por la actuación de mala fe.

El deber de diligencia está limitado por el Business Judgement Rule [o regla del juicio de los negocios] de la doctrina anglosajona que prácticamente limita la responsabilidad a la mala fe y a una decisión no informada. La jurisprudencia de nuestro país vecino ha establecido que la responsabilidad sólo opera en caso de fraude, ilegalidad, colusión y propósito deshonesto. Y aunque la decisión sea onerosa para la sociedad, si se tomó la providencia de recabar la información pertinente, la administración queda exonerada. En otras palabras, el deber de diligencia aplica en caso de culpa grave. No aplica por una mala decisión de negocios si se tomó de manera informada. Y, en este sentido, es importante tener en cuenta que las sociedades compiten en el mercado con otros actores y una decisión de negocios puede resultar fatal sin 
que por ello la administración incurra en negligencia; simplemente las condiciones del mercado pueden operar en contra. La positivización en nuestro ordenamiento jurídico -vía la LMV- obliga a los consejeros a informarse de los asuntos sociales; a requerir la presencia de directivos relevantes y expertos; así como solicitar el aplazamiento de las sesiones del consejo cuando un consejero no haya sido convocado. Tipifica como caso específico de negligencia -o falta al deber de diligencia- la no asistencia a las sesiones del consejo de administración; el ocultamiento de información al consejo; y la infracción a los deberes legales y estatutarios de la sociedad.

El deber de lealtad, que es complementario del de diligencia, impide a los socios participar en las decisiones sociales si tienen conflicto de intereses. No obstante la jurisprudencia norteamericana limita este deber, aun en el caso de un aparente conflicto de intereses, cuando la decisión se haya tomado de acuerdo con la regla del negocio u no exista malversación o imprevisión. La LMV establece las líneas maestras de este deber, ordenando a los consejeros y al secretario del consejo guardar confidencialidad con respecto a la información social; y les ordena abstenerse de participar en un asunto en el que tengan conflicto de intereses. Para una mejor aplicación de este deber la LMV tipifica siete casos que van desde participar en votaciones en las que tienen conflicto de intereses; pasando por el uso de información y patrimonio sociales en beneficio propio; hasta la explotación y uso a favor propio y de terceros de la información privilegiada. Por último, la LMV contempla una acción específica por responsabilidad en caso de falta a los deberes de diligencia y de lealtad que consideramos de vital importancia para su efectivo cumplimiento.

\section{Bibliografía}

Bisbal I. Mendez, J. (1997) “El gobierno de las compañías mercantiles: teoría y práctica” Revista de Derecho Mercantil 226, pp. 1673-1698

Castañeda Ramos, G. (2010) “Evolución de los grupos económicos durante el período 1940-2008”. En Kunz Ficker, S (Coord): Historia económica general de México, de la Colonia a nuestros días. El Colegio de México, Secretaría de Economía, México 
Gobierno corporativo y grupos económicos en México: especial referencia...

Consejo Coordinador Empresarial (2010) Código de Mejores Prácticas Corporativas, México.

Chavarín Rodríguez, R. (2010) Banca, Grupos Económicos y Gobierno Corporativo en México, Centro de Estudios Espinosa Yglesias, México

(2006) "La arquitectura organizacional y gobierno corporativo de los grupos económicos en México”. En: Ciencia Ergo Sum Vol 13 No 2 pp. 193-199

Cruz Reyes, G. (2006) La nueva Ley del Mercado de Valores Deloitte, México

Fernández Izquierdo, M.A. et al (2008) "El Gobierno Corporativo como motor de la responsabilidad Social Corporativa” Col. Economia i Gestió No 8, Grupo de Investigación SoGReS Publications de la Universidad Jaume I, Castelló de la Plana.

Galindo Sifuentes E. (2007) Derecho Mercantil 2 ${ }^{\text {a }}$ Ed, Editorial Porrúa, México

García Velasco, G. (2005) Las minorías en las sociedades anónimas, Editorial Porrúa, México

Guadarrama López, E. (2008) La Sociedad Anónima en el Derecho Mexicano. Consideraciones particulares sobre la Anónima Bursátil, Editorial Porrúa, México

Guerra Martín, G. (2003) El gobierno de las sociedades cotizadas estadounidenses, Monografía asociada a la Revista de Derecho de Sociedades 20, Aranzadi, Madrid.

Larrea Martínez, G. y Vargas García, S (2007) Apuntes de gobierno corporativo, Universidad Panamericana, Editorial Porrúa, Escuela Libre de Derecho, México.

López de Silanes, F. (2009): "Gobierno corporativo y mercados financieros en la OCDE y América Latina: lecciones para los cambios regulatorios después de la crisis financiera”. En: G. Nuñez, A. Oneto y G. Mendes de Paula (Coords) Gobernanza corporativa y desarrollo de mercados de capitales en América Latina, Colombia: CEPAL, pp. 45-106.

Morera Camacho C. (1998) El Capital Financiero en México y la Globalización, limites y contradicciones UNAM-Editorial ERA-Instituto de Investigaciones Económicas, México

Nava Vázquez, C. (2006) “Mejores prácticas de gobierno corporativo en México y Estados Unidos: los deberes de lealtad y diligencia en la nueva ley del 
mercado de valores" en A Quintana y A Envía (Coords) Panorama Internacional de Derecho Mercantil, Culturas y Sistemas Jurídicos Comparados, Tomo 1, México, Instituto de Investigaciones Jurídicas de la UNAM.

OCDE (2007) Principios de Gobierno de la OCDE, París, Organización para la Cooperación y Desarrollo Económico.

Paz Ares, C. (2003) "La responsabilidad de los administradores como instrumento de gobierno corporativo" en InDret No 4, pp. 1-60.

Salas Porras, A. (2007): "Los grupos mexicanos y coreanos ante la crisis del estado” en Foro Internacional Vol. XLVII No. 188, pp. 300-339.

--------- (2006): “Fuerzas centrípetas y centrífugas en la red corporativa mexicana (1981-2001)” en Revista Mexicana de Sociología, No 2, pp. 331-375.

Santiago Castro, M et al. (2009) "Prácticas de gobierno corporativo en América Latina” en Revista Latinoamericana de Administración No 43 pp. 26-40.

Sánchez Calero, F. (2009) Instituciones de Derecho Mercantil Tomo I Editorial Aranzadi, Madrid

Santos Castroviejo, I. y Arcudia Hernández, C. (2012) "La élite del poder económico en México, configuraciones de red corporativa tipo "grupo económico y modo de regulación dominante”. En: Revista de Economía Crítica No 14 pp. 6-36 